\title{
A COMPARATIVE STUDY OF EFFICACY OF PEFLOXACIN VERSUS PEFLOXACIN AND ALKALINISING AGENT IN THE TREATMENT OF URINARY TRACT INFECTION
}

\author{
Ghosh Amit Kumar ${ }^{* 1}$, Dalai Chanchal Kumar ${ }^{2}$, Das Anup Kumar ${ }^{3}$ \\ ${ }^{1}$ Associate Professor, Department of pharmacology, R.G.Kar medical college \& hospital, Kolkata, India-700004 \\ ${ }^{2}$ Assistant Professor, Department of pharmacology, college of medicine \& jnm hospital, kalyani, nadia, India- 741235 \\ ${ }^{3}$ Professor \& HOD, Department of pharmacology, R.G.Kar medical college \& hospital, Kolkata, India-700004 \\ *Corresponding Author's Email-21111969amitghosh@gmail.com, Mob-9432305660
}

\begin{abstract}
:
Background: In urinary tract infection (UTI) alkalinisation of urine is a common practice, which may change or altered the effect of some antimicrobial treatment. Pefloxacin, a well-known fluoroquinolone used for treatment of urinary tract infection is found to be effective. On this background, the study was done to evaluate the effect of pefloxacin in presence of alkalinising agent.

Aim: To evaluate the antimicrobial effect of pefloxacin both in presence and absence of alkalinising agent.

Settings and Design: Prospective, interventional, randomized, assessor blind, fixed dose with two parallel treatment groups and unicentric.

Results: Pefloxacin was effective in $100 \%$ when used alone, but in presence of disodium hydrogen citrate, the urinary alkalinising agent solution, effectivity of pefloxacin came to $45.71 \%$.

Conclusion: To conclude, it is said that the efficacy of pefloxacin has been reduced after alkalinisation of urine.

Key Words: UTI, Pefloxacin, disodium hydrogen citrate
\end{abstract}

\section{INTRODUCTION:}

Urinary tract infection (UTI) is a common and painful human illness affecting all age groups and sexes, fortunately, is rapidly responsive to modern antibiotic therapy. ${ }^{1}$ But now a days, treatment of UTI has supposed to be a problem to the clinician due to emergence of resistance strains of bacteria to various antimicrobials used over the years. There has been a growing rate of resistance among common urinary tract pathogens, such as Escherichia coli, to traditional antimicrobial therapies including the "gold standard" trimethoprimsulfamethoxazole (TMP-SMX). Consequently, fluoroquinolone antimicrobial agents have taken on an expanding management role for UTIs. In fact, the recent Infectious Diseases Society of America clinical management guidelines for UTI recommend fluoroquinolones as first-line therapy for uncomplicated UTI in areas where resistance is likely to be of concern. Fluoroquinolones have demonstrated high bacteriologic and clinical cure rates, as well as low rates of resistance, among most common uropathogens. ${ }^{2}$ Fluoroquinolones have been recommended as the drugs of choice for the empirical treatment of uncomplicated and complicated urinary tract infections (UTIs) caused by trimethoprimsulfamethoxazole-resistant uropathogens. ${ }^{3}$ Among the floroquinolones, pfloxacin is commonly prescribed for the treatment of UTI.

Alkalinisation of urine by disodium hydrogen citrate solution is a common practice for symptomatic improvement by most of the physician. Urinary alkalinising agents such as sodium citrate have been given by mouth to relieve the pain of cystitis caused by UTI. ${ }^{4}$

So, during treatment of UTI, fluoroquinolones along with alkalinising agents are used simultenously. But whether the alkalinisation of urine increases the efficacy of fluoroquinolones in treatment of UTI is not known clearly.

On this background, this study was carried out to assess the effect of alkalinisation of urine on the efficacy of pefloxacin, a newer fluoroquinolone in the treatment of uncomplicated UTI.

\section{MATERIALS AND METHODS:-}

\section{ETHICAL CONSIDERATIONS:}

The study protocol, informed consent form (in Bengali, Hindi \& English) and case report form (CRF) were submitted to the ethics committee of R.G.Kar Medical College \& Hospital, Kolkata West Bengal for approval. Subject recruitment commenced only after approval was obtained. Written informed consent was taken from each participant. Illiterate individuals gave their fingerprint (left thumb impression) instead of signature in the presence of an appropriate witness.

\section{SUBJECT SELECTION CRITERIA:}

The subjects who had willingly participated were enrolled on the basis of inclusion and exclusion criteria. Patients with uncomplicated UTI (sensitive to pefloxacin irrespective of causative organism) aged between 18 to 60 years of either sex were included in the study. Where pregnant and lactating mothers, any haematological diseases, diabetes mellitus, any malignancy, any urinary tract abnormality, any liver/kidney disorders, known allergy to flouroquinolones and history of any other antibiotic intake within 2 weeks prior to study and during study period, were excluded from the study.

\section{STUDY SETTING}


The study was conducted in the Department of Medicine, R. G. Kar Medical College \& Hospital, Kolkata, West Bengal.

Screening: Through General Medicine OPD of R.G.K.M.C.

\section{Recruitment and Drug dispensing: Through General} Medicine OPD of R.G.K.M.C.

Data compilation and Statistical analysis: In Department of Pharmacology, R.G.K.M.C.

\section{STUDY DESIGN:}

The current study was designed as a prospective, interventional, randomized, assessor blind, fixed dose with two parallel treatment groups and unicentric.

Study Period: The study was conducted from March 2012-December 2012.

\section{Regulatory Considerations:}

Since the study medication (Pefloxacin) was already marketed in India at the time of study inception, no separate regulatory approval from the Drugs Controller General of India was sought.

\section{Study Groups and Randomization:}

A random number table generated by computer in blocks of 100. The large block size reduced the risk of allocation bias. The study coordinator was the only person with access to the randomization. According to the randomization sequence subjects fulfilling the selection criteria were received either pefloxacin $400 \mathrm{mg}$ twice daily orally for consecutive 5 days or pefloxacin in doses of 400 mg BD and alkalinising agent (disodium hydrogen citrate $1.4 \mathrm{gm} / 5 \mathrm{ml}$ ) $10 \mathrm{ml}$ thrice daily orally for consecutive 5 days.

Blinding: Study was designed as assessor-blind study. The identity of the study group was blinded to the assessor physician (microbiologist and pathologist).

\section{METHODS}

After recruitment, a detailed medical history was taken followed by thorough clinical examination which included both general and systemic examination. This was followed by examination of urine i.e. routine urine examination $(\mathrm{pH}$, pus cells, R.B.C, epithelial cells, albumin/ cast), culture and sensitivity. Routine laboratory investigations $(\mathrm{Hb} \%$, TC, DC, ESR, FBS, PPBS urea, creatinine, Liver function test) and imaging (straight $\mathrm{x}$-ray abdomen/K.U.B, intravenous urography, Ultrasonography) were done in all subjects. . The patients with UTI were screened from OPD with one/more of the following criteria: dysurea, increased frequency of urination, decreased amount of urine passed, high coloured urine, fever, supra-pubic tenderness, palpable bladder. Following the above selection criteria 70 patients were included in the study.

After screening, the patients who fulfilled the selection criteria except the culture sensitivity report (which would be available after 72 hours) were randomized and called for baseline visit on the same day.

The first dose of study medication was given in this $1^{\text {st }}$ day. A urine specimen was obtained at baseline for routine analysis and for culture /sensitivity testing before administration of the drug.

On next visit at $8^{\text {th }}$ day of treatment clinical evaluation was done as well as bacteriological tests were repeated.

Bacteriological and clinical effectiveness were reassessed on $15^{\text {th }}$ day, and a repeat course of pefloxacin was given to those patients whose urine report showed persistence of organism.

On $22^{\text {nd }}$ day urine samples were recollected from these patients and reassessed.

\section{Statistical analysis:}

Data was processed and analyzed at the Department of Pharmacology, R.G.K.M.C, Kolkata. Analysis was done only after CRF of the last subject was in, data had been entered, and the computer database cleaned and locked. Statistical analysis was performed using graph pad-instat-3 software.

Dichotomous events were analyzed by using the Person's two sided Chi-square comparison Statistical significance was defined as $\mathrm{P}$-value $<0.05$.

\section{RESULTS AND ANALYSIS:}

All the 70 cases were confirmed as UTI on the basis of urine culture of the patients Among the 70 patients in the study, female were more sufferer in UTI than male (female: male- 64:6 ). Their mean age was 29.8 years and mean body weight was $48.52 \mathrm{~kg}$.

\section{Result of culture of urine:}

Urine culture reports were analysis. The various organism isolated from the urine culture were tabulated in table 1 and figure 1.

Table 1: Shows distribution of causative organisms of UTI

\begin{tabular}{|l|c|c|}
\hline Causative organism & Numbers & Percentage (\%) \\
\hline Escherichia coli & 58 & $82.86 \%$ \\
\hline Klebsiella & 6 & $7.14 \%$ \\
\hline Proteus & 3 & $4.28 \%$ \\
\hline Pseudomonas & 2 & $2.85 \%$ \\
\hline $\begin{array}{l}\text { Ureaplasm } \\
\text { urealyticum }\end{array}$ & 1 & $1.42 \%$ \\
\hline
\end{tabular}

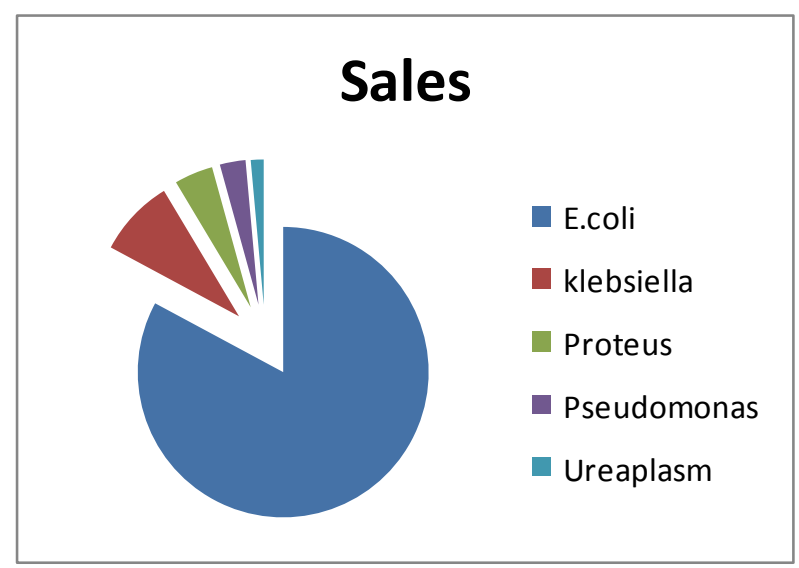

Figure 1: Shows distribution of causative organisms of UTI 
Table 2: shows analysis of the clinical and bacteriological findings:

\begin{tabular}{|c|c|c|c|c|c|c|c|c|c|}
\hline \multirow[t]{3}{*}{ SYMPTOMS } & \multirow[t]{3}{*}{$\begin{array}{l}\text { NO. OF } \\
\text { CASES }\end{array}$} & \multicolumn{2}{|c|}{$\begin{array}{l}\text { URINARY } \\
\text { FINDINGS }\end{array}$} & \multirow{2}{*}{\multicolumn{6}{|c|}{$\begin{array}{l}\text { MICROSCOPICAL \& } \\
\text { BACTERIOLOGICAL OBSERVATIONS } \\
\text { IN POSITIVE CASES }\end{array}$}} \\
\hline & & $+\mathrm{VE}$ & $-\mathrm{VE}$ & & & & & & \\
\hline & & & & $\mathrm{P}$ & B & $\mathrm{P}+\mathrm{B}$ & $\mathrm{P}+\mathrm{C}$ & $\mathrm{B}+\mathrm{C}$ & $\mathrm{P}+\mathrm{B}+\mathrm{C}$ \\
\hline 1.dysurea & 20 & 16 & 4 & 1 & 1 & 3 & 1 & 1 & 9 \\
\hline $\begin{array}{l}\text { 2.increasedfrequency of } \\
\text { Urination }\end{array}$ & 12 & 10 & 2 & 1 & 1 & 1 & - & 1 & 7 \\
\hline $\begin{array}{l}\text { 3.dysurea }+ \text { increased } \\
\text { Frequency }\end{array}$ & 14 & 14 & 0 & - & - & 1 & - & 2 & 11 \\
\hline 4. dysurea + fever & 7 & 7 & 0 & - & 1 & 2 & 1 & 1 & 2 \\
\hline 5.fever + frequency & 4 & 3 & 1 & - & - & - & - & 1 & 2 \\
\hline 5. dysurea + frequency+fever & 3 & 3 & 0 & - & 1 & - & - & 1 & 1 \\
\hline 7.pain & 4 & 2 & 2 & - & - & - & - & - & 2 \\
\hline 8.high colour urine & 6 & 4 & 2 & 1 & 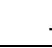 & 1 & - & - & 2 \\
\hline TOTAL & 70 & 59 & 11 & 3 & 4 & 8 & 2 & 7 & 36 \\
\hline
\end{tabular}

\section{RESULT OF TREATMENT:}

Clinical and bacteriological evaluation were done again after 5 days of therapy. It was seen that the 35 cases treated with pefloxacin alone were completely cured $(100 \%)$ but patients those were received pefloxacin along with alkali solution (35 patients) the treatment success were very low; that was only $16(45.71 \%)$ that was statistically significant $(\mathrm{p}<0.001)$. Cases were designated bacteriologically as eradicated, when urine samples were found to be sterile and persistent when the urine specimens showed bacteria microscopically or growth on culture or both.

\section{RESULT OF RETREATMENT:}

Those cases which were not eradicated by pefloxacin plus disodium hydrogen citrate solution were again subjected to consecutive 5 days therapy with pefloxacin alone. It is seen that all the cases which failed to show eradication by treatment with pefloxacin with disodium hydrogen citrate solution could be eradicated by another consecutive 5 days therapy with pefloxacin alone.

\section{DISCUSSION:}

Urinary tract infection is common ailment affecting predominantly females between ages of 20 to 45 years. In this study female: male ratio is 10.67: 1 which corroborates well with the text book figure though incidence varies at different stages of life.

The present comparative study of bacteriological and clinical efficacy showed $100 \%$ of patients were relieved of symptoms and signs when pefloxacin alone were used, whereas only $45.71 \%$ of patients receiving pefloxacin + disodium hydrogen citrate solution showed eradication and clinical cure with a $p$ value of $<0.001$ that was significant.
Of the 35 patients in the group treated with disodium hydrogen citrate solution + pefloxacin, only $16(45.71 \%)$ patients were found to be cured and the rest patients were then subjected to a further treatment of 5 days with pefloxacin alone (400 $\mathrm{mg}$ BD) and showed complete eradication of the organism.

Therefore, we can say that antimicrobial efficacy of pefloxacin showed diminution of action in the presence of alkalinisation of urine. It is known that gastrointestinal absorption of pefloxacin is reduced by antacids containing salts of magnesium, aluminium or calcium only. ${ }^{5}$

However, any mention of pharmacokinetic or pharmacodynamic drug-drug interaction between pefloxacin and disodium hydrogen citrate is not found in the literature.

Though appropriate explanation for this diminution of action of pefloxacin can not be found, but there are few facts to be mentioned. It is known that, antibacterial used to treat UTI need to be excreted in adequate concentration in urine. ${ }^{4}$ Unlike other fluoroquinolones major pathway of excretion of pefloxacin is non-renal. ${ }^{6}$

It is known that, pefloxacin has been metabolized in liver to N-Desmethyl pefloxacin (Norfloxacin). Norfloxacin is least soluble at a urinary $\mathrm{pH}$ of $7.5 .^{7}$ it was observed the presence of crystals of fluoroquinolones particularly of norfloxacin in the alkaline urine. ${ }^{8}$ So, this may also occur following administration of pefloxacin, as its major metabolite is norfloxacin.

Thus, fewer amounts of active metabolites of pefloxacin (Norfloxacin) present in urine is further reduced by crystalisation and precipitation of Norfloxacin in alkaline urine $^{8}$ 
Due to the above reasons, the concentration of pefloxacin and its major metabolite, norfloxacin present in alkaline urine may be less than the required minimum inhibitory concentration.

The present study had some limitations

- The study did not include placebo group so that it is impossible to determine absolute level of efficacy.

- It was not possible to measure the blood concentration of both drugs.

\section{REFERENCES}

1. Kalpana Gupta,Barbara W. Trautner. 288 Urinary tract infections, pyelonephritis, and prostritis. Longo DL, Fauci AS, Kasper DL, Hauser SL, Jameson JL, Loscalzo J editors. Harrison's Principles of Internal Medicine. $18^{\text {th }}$ ed. New York. Mc Graw Hills, 2012:2388-9.

2. Schaeffer AJ. The expanding role of fluoroquinolones. Dis Mon. 2003; 49(2):129-47.

3. Chen $\mathrm{YH}, \mathrm{Ko} \mathrm{WC}$, Hsueh PR. The role of fluoroquinolones in the management of urinary tract infections in areas with high rates of fluoroquinolone-resistant uropathogens. Eur J Clin Microbiol Infect Dis. 2012; 31(8):1699-704.

4. Sean C Sweetman. Martindale- The Complete Drug Reference. $36^{\text {th }}$ ed. London Chicago. Pharmaceutical Press, 2009; 199.

5. Sean C Sweetman. Martindale- The Complete Drug Reference, $36^{\text {th }}$ ed. London Chicago. Pharmaceutical Press, 2009; 246.
- The trial was not double blind study.

\section{CONCLUSION}

In spite of the above limitation, it can be said that pefloxacin should not be co-prescribed with alkalinizing agents for the treatment of UTI. Further studies with large sample size will required for further evaluation.

6. William A. Petri Jr. Section VII Chemotherapy of microbial disease, Sulfonamides, Trimethoprim-Sulfamethoxazole, Quinolones, and agents for urinary tract infections. Laurence L Brunton, Bruce A. Chabner, Bjorn C. Khollmann. Goodman \& Gillman's -The Pharmacological Basis of Therapeutics. $12^{\text {th }}$ ed. New York. Mc Graw Hill, 2011; 1473.

7. Sean C Sweetman. Martindale- The Complete Drug Reference, $36^{\text {th }}$ ed. London Chicago. Pharmaceutical Press, 2009; 313.

8. Lacely RW and Macmmury RV.In vitro activity of norfloxacin in urine. The American J. of Med.1987; 82, 3-17. 